\title{
Estudo da Interação Solo-Estrutura em um difício com Patologias de Fundações na Região Metropol- itana do Recife
}

Cavalcanti, C. S.

Escola Politécnica de Pernambuco Universidade de Pernambuco 50.720-001 - Recife, Brasil camixmila@hotmail.com
Gumão, A. D.

Escola Politécnica de Pernambuco

Universidade de Pernambuco

50.720-001 - Recife, Brasil

gusmao@ig.com.br
Sukar, S. F.

Escola Politécnica de Pernambuco

Universidade de Pernambuco

50.720-001 - Recife, Brasil

sfucale@yahoo.com.br

Resumo O artigo apresenta um caso real de monitoramento dos recalques, onde a medição dos recalques permitiu identificar o mau desempenho das fundações de um edifício com 26 lajes construído na Região Metropolitana do Recife - RMR. A partir dos resultados do monitoramento do prédio, foi concebido e executado um reforço para as suas fundações. O reforço foi feito com o prédio ocupado e a estabilização dos recalques foi conseguida..

Abstract The paper presents a real case of monitoring settlements, where the measurement of the settlements identified the bad performance of the foundations of a building with 26 stories building in the Metropolitan Area of Recife. From the results of monitoring of the building was designed and implemented na reinforcement to its foundations. The reinforcement was made with the building occupied and stabilization of settlements was achieved. 


\section{Introdução}

Morfologicamente a Cidade do Recife apresenta duas paisagens muito distintas: os morros e a planície. A ocupação da cidade com edificações de grande porte tem se dado, contudo, apenas no espaço confinado entre os morros e a orla marítima, que se constitui em uma grande planície de origem flúvio-marinha. Neste contexto geológico, o subsolo típico é muito variado. Encontram-se camadas de areia fina e média, de compacidade fofa, intercaladas ou seguidas por outras, seja de argila orgânica mole, seja de areia muito compacta ou arenitos bem consolidados. Os depósitos de argila orgânica mole e média são encontrados em cerca de $50 \%$ da área da planície, muitas vezes em subsuperfície e com espessuras superiores a $15 \mathrm{~m}$ [1].

Por tudo isto, a prática atual de fundações no Recife é fortemente direcionada pelas características geológico-geotécnicas do subsolo, ainda que outros fatores influenciem na escolha e sejam assim encontrados diversos tipos de fundação na cidade [2].

Em função dessa diversidade de perfis geotécnicos presentes na RMR, tem sido prática usual o monitoramento dos recalques de edifícios. Para se conseguir a desmistificação da medição dos recalques, algumas estratégias de convencimento têm sido apresentadas aos construtores: (i) o monitoramento deve ser encarado como um controle tecnológico da obra, a exemplo de tantos outros, como o controle da resistência do concreto; (ii) o monitoramento permite um melhor entendimento do comportamento de uma edificação, e uma retroanálise dos parâmetros dos solos, o que tem conduzido a projetos mais arrojados (e nem por isso menos seguros); (iii) o monitoramento permite identificar com mais segurança as causas de patologias que possam surgir nos prédios, onde normalmente a fundação é colocada em suspeita [3].

Este artigo apresenta um caso de monitoramento dos recalques, onde a instrumentação permitiu identificar o mau desempenho das fundações de um edifício com 26 lajes construído na orla de Jaboatão dos Guararapes, na RMR. A partir dos resultados do monitoramento do prédio, foi concebido e executado um reforço para as suas fundações.

\section{Caracterização da Estrutura}

Trata-se de uma estrutura aporticada de concreto armado com 26 lajes e 62 pilares, sendo 18 na lâmina e 44 na periferia. As cargas verticais permanentes nos pilares da lâmina variam de 3676 a $21705 \mathrm{kN}$, enquanto que na periferia variam de 100 a $1870 \mathrm{kN}$. Há ainda esforços devido à ação do vento na estrutura.
Há um pavimento semi-enterrado na cota $-1,90 \mathrm{~m}$ em relação ao nível de meio fio da avenida principal da orla. As fundações projetadas e executadas são superficiais do tipo sapatas isoladas ou associadas, assentes no terreno natural na cota $-4,40$.

\section{Caracterização do Terreno de Fun- dação}

Durante a fase de projeto do edifício, foram feitas várias sondagens de reconhecimento mistas (SPT e rotativa). As Figuras 1 e 2 mostram duas sondagens típicas do terreno, onde pode ser observada a presença de uma espessa camada de argila siltosa com matéria orgânica (ou silte argiloso), cinza escuro, muito mole a mole, entre as cotas 14,50 a $-24,00$.

O nível d'água freático aparece entre as cotas $-3,50 \mathrm{e}$ $-4,50$. Alguns fatos relevantes observados nas sondagens devem ser ressaltados: (i) a espessura do arenito diminui na direção da praia (leste) e na direção sul; (ii) na parte sudeste da área da lâmina, praticamente o arenito desaparece; (iii) apenas a Sondagem SP01 apresenta uma baixa resistência a penetração (NSPT) na cota de fundação (4,40 ), o que pode indicar a presença de um bolsão de areia fofa na parte sudeste do terreno.

A Figura 3 apresenta a fôrma das sapatas da lâmina do prédio. Observa-se que as sapatas dos pilares $\mathrm{P} 2$ a $\mathrm{P} 8$ apresentam um formato pouco usual para sapatas. A taxa de trabalho das sapatas é da ordem de 450kPa para o carregamento sem a ação do vento.

\section{Histórico}

O prédio foi construído no final da Década de 80 (provavelmente entre 1987 e 1990), e sua ocupação pelos moradores foi iniciada no início da década de 90. 


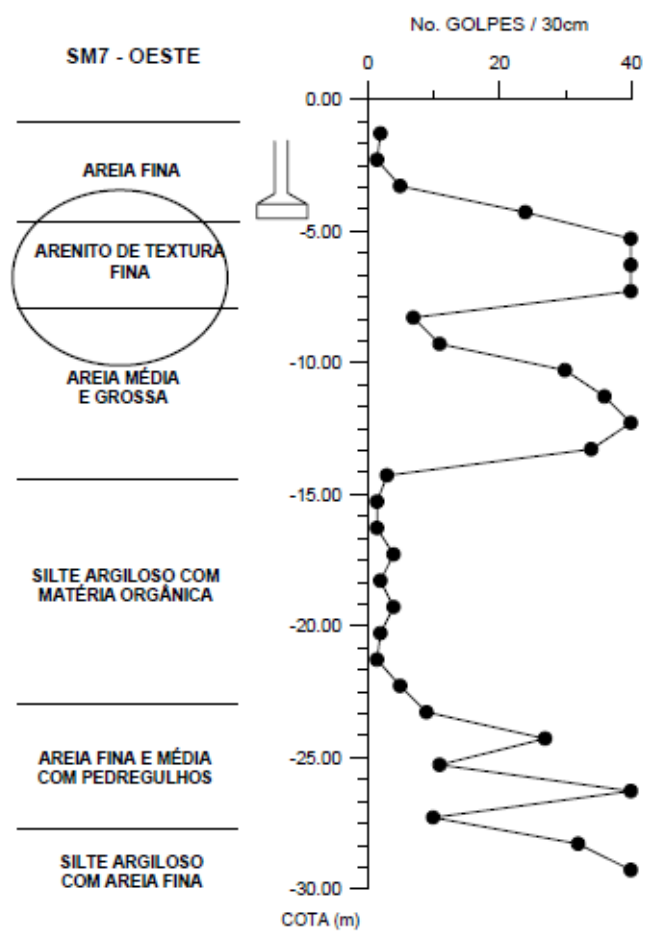

Fig. 1. Sondagem de reconhecimento - Lado Oeste.

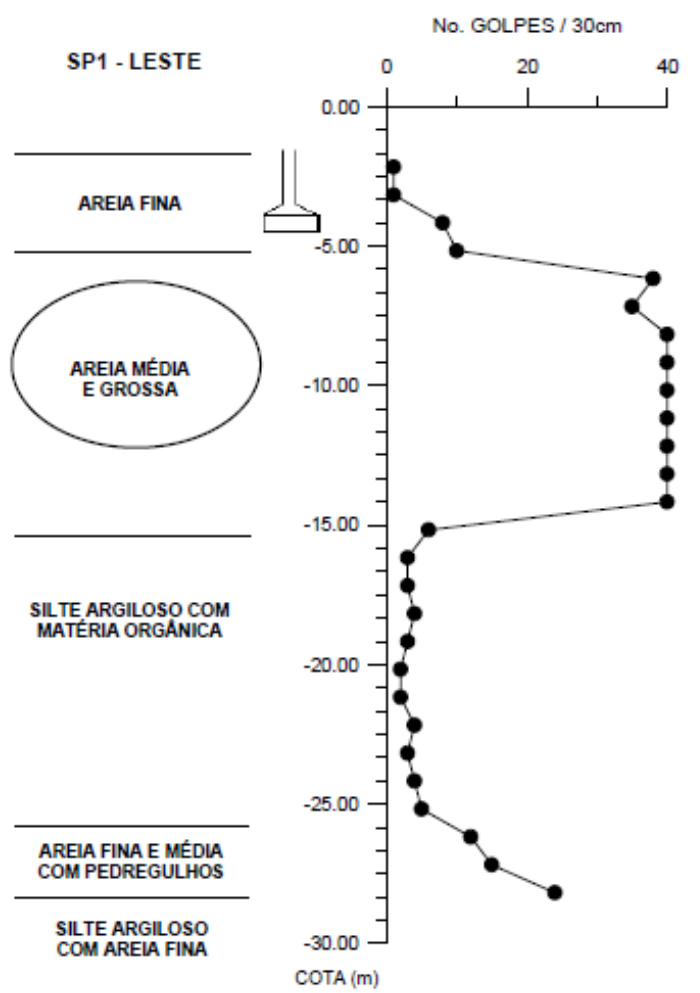

Fig. 2. Sondagem de reconhecimento - Lado Leste.
Segundo relatos contidos nos relatórios e entrevistas com alguns moradores, os danos no prédio começaram a surgir desde o início da sua ocupação. Desde, então, estes danos foram se agravando, especialmente nos dois pavimentos inferiores de garagem e no mezanino.

Os danos incluíam fissuras e trincas em alvenarias, vigas, lajes e pilares, além de um acentuado desaprumo do prédio nas direções leste e sul.

A partir de 1992 o prédio começou a ser monitorado com medições periódicas de recalques edesaprumo das fachadas. Além disto, havia um acompanhamento da evolução de algumas fissuras.

A Figura 4 mostra a curva de evolução dos recalques dos pilares da lâmina entre 1992 e 2002 . Observa-se que os recalques absolutos variaram de 74,4 a 123,3mm na última medição (21/08/2002), e que as leituras não mostravam uma tendência de estabilização. Nesse período, a velocidade parcial de recalques se manteve praticamente constante ao longo daqueles 10 anos, com valor aproximado de $25 \mu \mathrm{m} /$ dia, que corresponde a $9,1 \mathrm{~mm} /$ ano [2].

A Figura 5 mostra as curvas de isorecalques medidas na última medição. Observa-se que os maiores recalques ocorreram nos pilares localizados na área leste e sul do terreno (P11, P14, P16 e P18), e com isso houve um desaprumo do prédio.

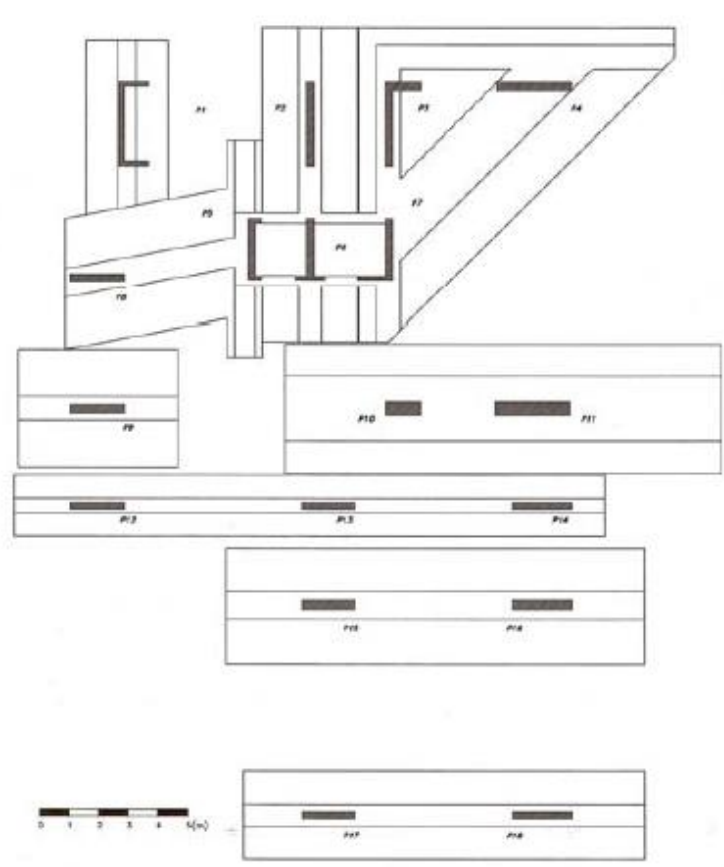

Fig.3. Fôrma das sapatas da lâmina do prédio. 


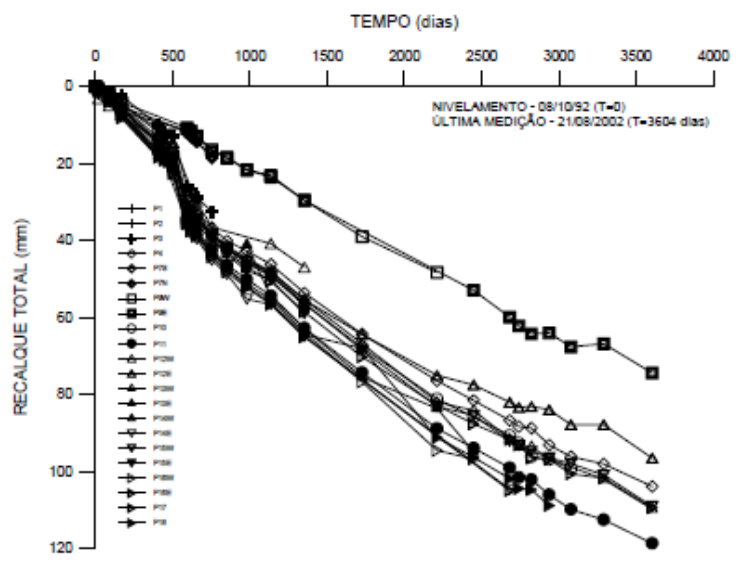

Fig. 4. Evolução dos recalques da lâmina do prédio entre 1992 e 2002.

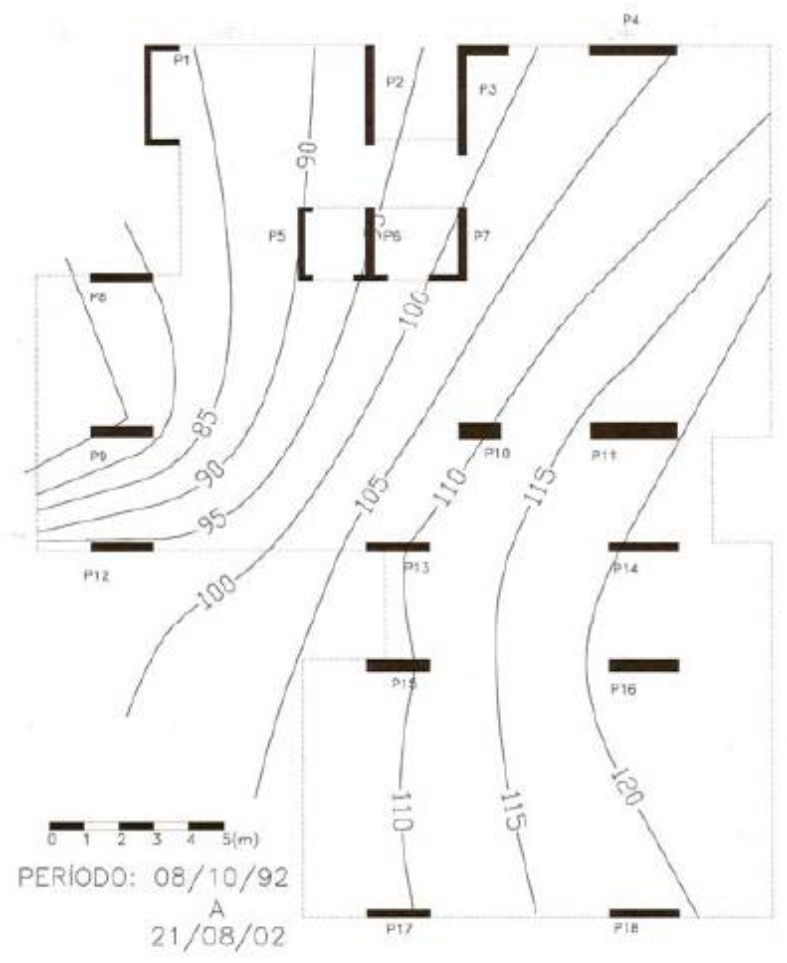

Fig. 5. Curvas de isorecalques da lâmina do prédio na última medição - antes do reforço (21/08/2002).

A Figura 6 mostra a evolução do desaprumo do prédio entre 1998 e 2000. Observa-se que houve um crescimento praticamente linear do desaprumo, cujo valor na direção leste $(1 / 175)$ já era superior a $1 / 200$, que normalmente é considerado como limite para estruturas desse tipo.

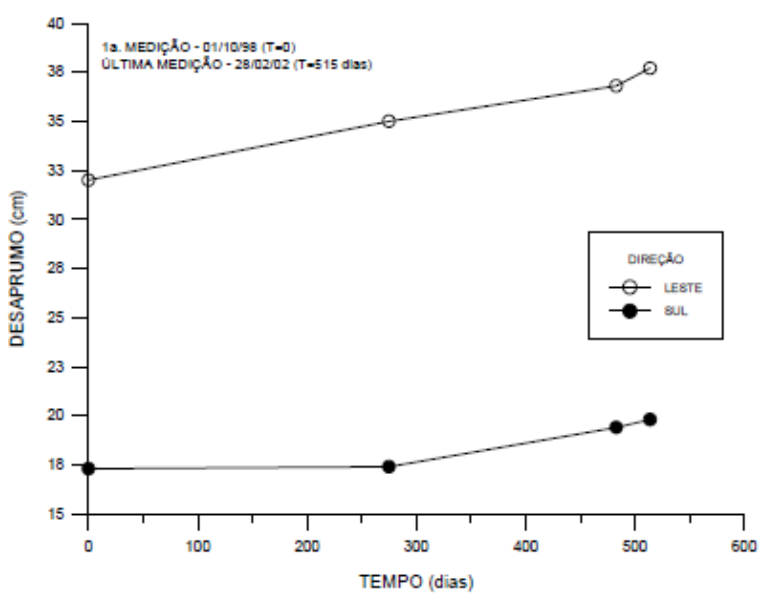

Fig. 6. Evolução do desaprumo do prédio entre 1998 e 2000 - antes do reforço.

É importante ressaltar que o excessivo desaprumo provoca uma translação do centro de gravidade do prédio para a sua frente, o que faz com que haja uma redistribuição de cargas na fundação do prédio. $\mathrm{O}$ acréscimo de carga nos pilares da frente do edifício pode ocasionar novos recalques diferenciais não previstos, aumentando ainda mais o desaprumo do prédio, e vice versa.

\section{Diagnóstico}

Com o objetivo de estabelecer um diagnóstico para os problemas que tinham surgido no prédio, foi feito um levantamento completo dos danos surgidos na edificação, especialmente nos dois pavimentos de garagem e no mezanino.

O levantamento mostrou que a maior parte dos danos com fissuras se localizava nos pavimentos de garagem, especialmente no trecho de ligação da torre do prédio com a sua periferia.

Diante do quadro de danos e dos resultados do monitoramento do prédio, concluiu-se que o diagnóstico era que a torre do prédio recalcou mais que a periferia, e que os pilares localizados na área leste e sul do terreno (P11, P14, P16 e P18), recalcaram mais que os demais, fazendo com que houvesse um desaprumo da estrutura da torre nas direções leste e sul. Como as estruturas da torre e da periferia estavam ligadas sem qualquer tipo de junta, houve um desaprumo da periferia no sentido inverso ao da torre, ou seja, nos sentidos oeste e norte (Fig. 7). Este mecanismo de movimentação do prédio justificou o aparecimento de todos os danos observados. 
No ano de 2002, após uma negociação com o condomínio do edifício, a construtora ficou responsável pela execução do reforço das fundações do prédio, para permitir a estabilização dos seus recalques.

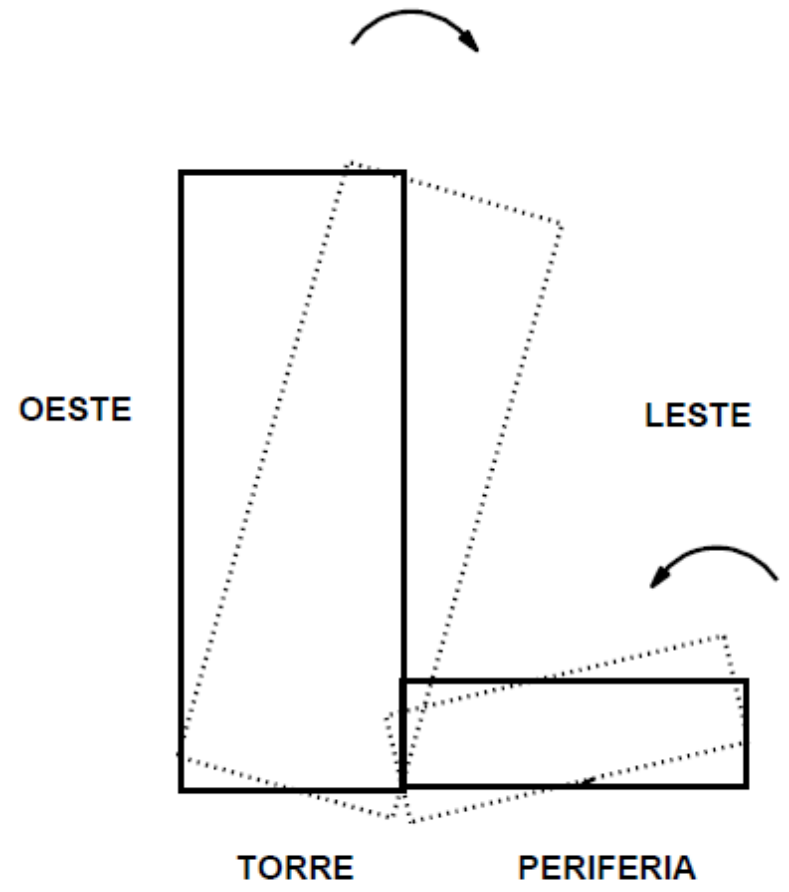

Fig. 7. Mecanismo de desaprumo da estrutura.

\section{Reforço das Fundações}

Inicialmente o projeto de reforço das fundações foi concebido com 172 estacas metálicas compostas por tubos vazados de $168 \mathrm{~mm}$ de diâmetro e $30 \mathrm{~m}$ de comprimento.

No sentido de se aferir a capacidade de carga das estacas de reforço, bem como as condições de sua execução, foi executada uma estaca piloto para a realização de uma prova de carga estática. A sua execução, no entanto, apresentou vários problemas (cravação, soldagem, etc), além de uma baixa produtividade (cerca de $8 \mathrm{~m}$ por dia).

Com isso, essa alternativa foi descartada e foi concebida uma nova solução de reforço, só que com microestacas injetadas. Tais estacas são do tipo autoperfurantes e consistem de barras trefiladas com um furo central em toda a sua extensão. Essas barras são unidas por luvas reforçadas, tendo em sua extremidade uma broca tricone reforçada com widea para perfuração de rochas brandas (arenito / calcáreo) e, com orifícios para injeção de calda de cimento.

A perfuração é executada concomitantemente com a injeção de calda de cimento através de processo rotativo, controlando-se a pressão, rotação e o avanço da composição, podendo reaproveitar a calda de cimento, proveniente da perfuração de arenitos e das camadas arenosas. Ao se atingir o comprimento final de perfuração, a microestaca estará pronta, acabada, devendo-se apenas aguardar o tempo de cura da calda de cimento para se executar a sua incorporação à estrutura

Devido às características das fundações existentes e do subsolo, nos locais previstos para as microestacas foram executados furos nos blocos de elevação e nas sapatas de concreto armado. Esses furos foram executados com equipamentos especiais, providos de motores de alta rotação e embreagem eletrônica, de modo a permitir que coroas diamantadas perfurem o concreto e cortem as barras de aço.

Concluída a perfuração das peças de concreto, foram executadas perfurações no arenito existente no subsolo com o auxílio de brocas tricônicas e sapatas de widea com diversos diamantes crescentes, até se atingir o diâmetro estipulado no projeto $(260 \mathrm{~mm})$.

Foi, então, executada uma microestaca piloto com cerca de $28 \mathrm{~m}$ de comprimento, onde foi realizada uma prova de carga a compressão. A prova de carga foi levada até uma carga máxima de compressão de $1979 \mathrm{kN}$, onde apresentou sinais de ruptura (Fig. 8).

Diante de tal resultado e do fato do problema do prédio não se tratar de instabilidade das fundações, mas de recalques excessivos, foi fixado um fator de segurança global de ruptura da estaca de 1,70 e uma carga admissível de $1150 \mathrm{kN}$. Ressalta-se pela curva carga-recalque, para a estaca mobilizar essa resistência de $1150 \mathrm{kN}$ o recalque necessário foi de $5 \mathrm{~mm}$.

A concepção inicial do projeto previa o reforço das fundações de todos os pilares da lâmina do prédio. Posteriormente, em função de discussões técnicas entre os diferentes profissionais envolvidos, ficou definido que o reforço deveria ser executado em duas etapas:

- $1^{\mathrm{a}}$ etapa: contemplava as sapatas SP $(17+18)$, SP (15+16), SP $(12+13+14)$, SP (10+11) e SP9.

- $\quad 2^{\mathrm{a}}$ etapa: contemplaria as sapatas dos pilares P1 a P8, e só seria executada se a $1^{\mathrm{a}}$ etapa não conduzisse à estabilização dos recalques do prédio. 
Para o cálculo das cargas atuantes nas estacas, foram considerados os cenários de carregamento permanente e de atuação do vento em ambas as direções. Para a distribuição das estacas apresentada no projeto, a carga máxima nas estacas foi igual a $1215 \mathrm{kN}$, ou seja, cerca de $6 \%$ acima da carga nominal de projeto fixada a priori. Como se tratava de um cenário com carregamento transitório, este valor foi considerado como aceitável.

Finalmente, para a definição da ordem de reforço das sapatas, foi feita uma análise de interação soloestrutura considerando-se os recalques medidos. Essa análise permitiu que fosse estabelecida uma ordem de execução das estacas que evitasse a formação de "núcleos de grande rigidez", e que pudesse concentrar o carregamento do prédio em poucos pilares.

O projeto executivo de reforço previu as seguintes etapas (Figuras 9, 10 e 11):

- Execução de bloco de elevação em concreto simples para permitir a subida do equipamento de execução das estacas, evitando o rebaixamento do nível d’água freático.

- Furação nas lajes das sapatas para ancoragem/colagem dos tirantes.

- Furação na lateral das vigas para ancoragem/colagem dos grampos.

- Execução das estacas, precedida da furação do concreto das lajes das sapatas e arenito.

- Execução dos tirantes, grampos e armadura complementar do bloco de incorporação, seguida da sua concretagem segundo uma ordem pré-estabelecida pela análise de interação solo-estrutura.

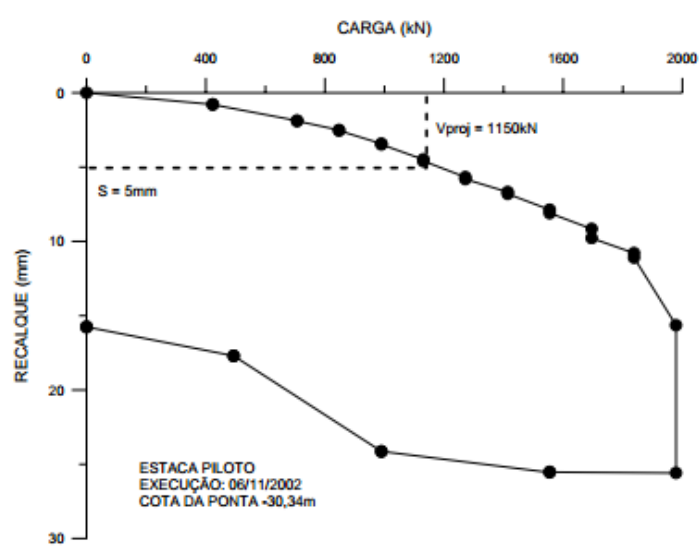

Fig. 8. Prova de carga a compressão na estaca piloto.
Foram executadas 102 estacas no período de 21/07/2004 a 19/04/2005, dentro das especificações do projeto. Todas as etapas do reforço foram executadas com o prédio em uso pelos moradores, interditando-se apenas o pavimento semi-enterrado por questões de logística. A Tabela 1 mostra as datas de finalização da incorporação dos blocos às sapatas existentes (22/12/2004 a 23/05/2005).

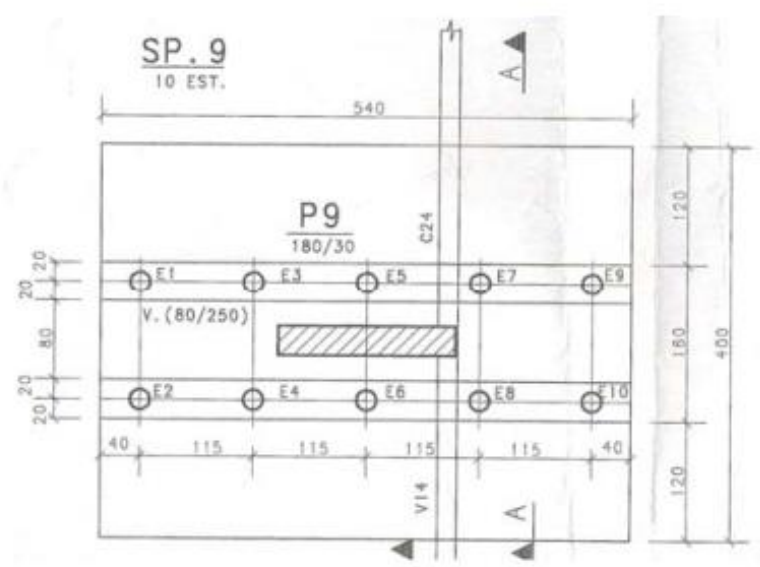

Fig. 9. Reforço da sapata P9 (Planta).

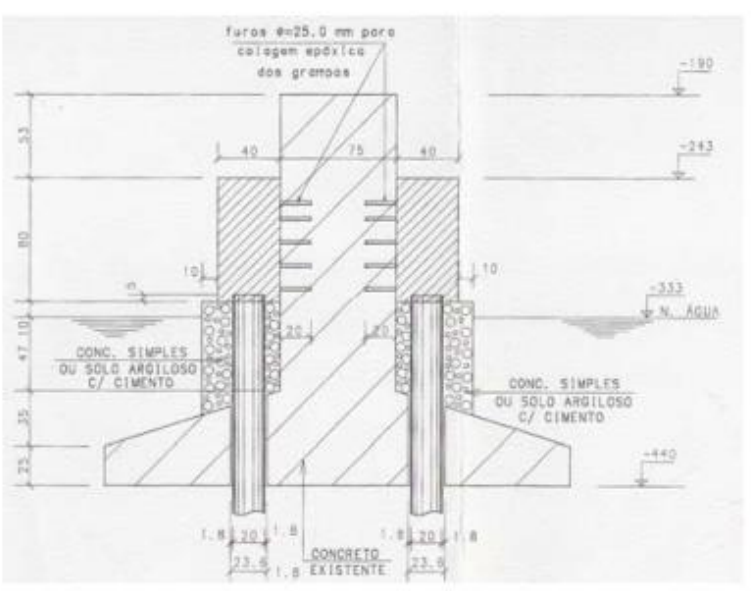

Fig. 10. Reforço da sapata P9 (Corte). 


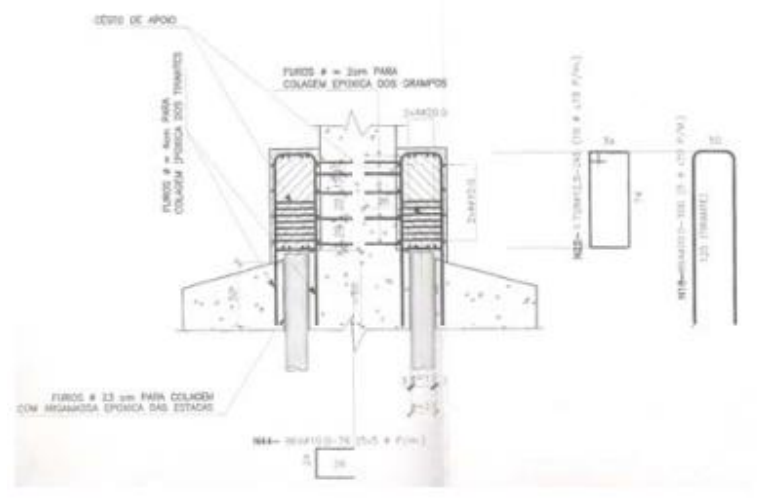

Fig. 11. Armação do reforço da sapata P9.

Tabela 1. Concretagem dos blocos.

\begin{tabular}{ccc}
\hline Bloco & $\begin{array}{c}\text { Número de } \\
\text { Estacas }\end{array}$ & $\begin{array}{c}\text { Data da } \\
\text { Concretagem }\end{array}$ \\
\hline P17+P18 & 18 & $22 / 12 / 04$ \\
P15+P16 & 26 & $14 / 01 / 05$ \\
P13+P14 & 12 & $17 / 02 / 05$ \\
P9 & 10 & $07 / 04 / 05$ \\
P12 & 06 & $07 / 04 / 05$ \\
P10+P11 & 30 & $23 / 05 / 05$ \\
\hline
\end{tabular}

\section{Monitoramento}

Antes do início da execução do reforço das fundações, o prédio já vinha sendo monitorado com medições de recalques. No entanto, foi necessária a instalação de novos pinos em todos os pilares da lâmina, pois alguns já estavam danificados. Houve ainda uma descontinuidade do monitoramento entre 21/08/2002 e 29/09/2003.

A Figura 12 apresenta a evolução dos recalques dos pilares da lâmina desde o início do reforço das fundações, enquanto a Figura 13 apresenta as curvas de isorecalques referentes ao período entre 2003 e 2008.

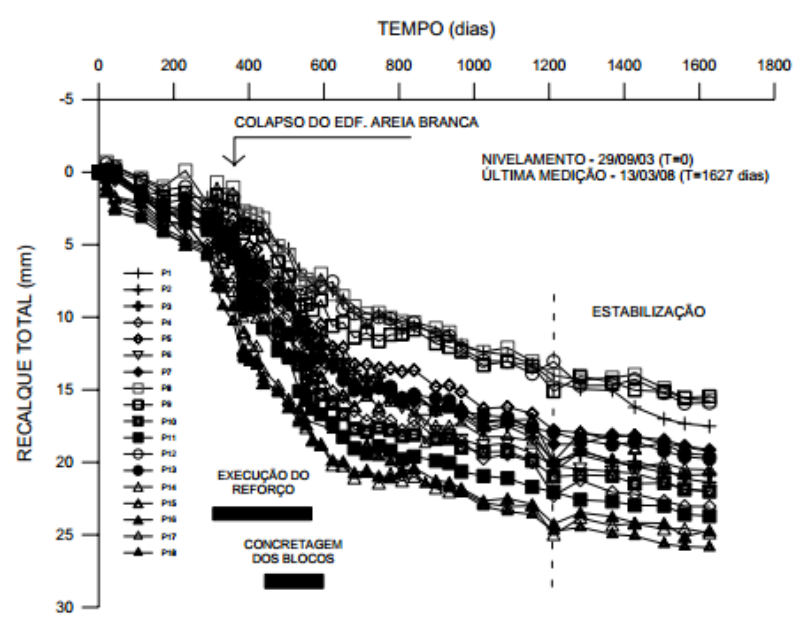

Fig. 9. Evoluçăo dos recalques da lâmina do prédio entre $2003 \mathrm{e} 2008$.

Notam-se alguns fatos bastante relevantes:

- $\quad$ Na fase de execução das estacas, houve uma aceleração dos recalques, decorrente do desconfinamento do terreno, bem como das injeções. Isso também foi observado em outras obras que tiveram reforço das fundações

- A estabilização dos recalques só ocorreu após um período aproximado de 600 dias depois da concretagem dos blocos, com o início da incorporação das estacas. O recalque médio nesse período foi de $7 \mathrm{~mm}$, ou seja, muito próximo do recalque necessário à mobilização da carga de projeto das estacas $(5 \mathrm{~mm})$.

Durante toda a execução do reforço, foi feito o monitoramento dos recalques. A frequência das leituras era alterada em função dos próprios resultados obtidos.

Também foi feito um acompanhamento das principais fissuras pelo engenheiro residente do condomínio do prédio. Após a estabilização dos recalques, observou-se que os danos existentes não mais evoluíram. Atualmente estão sendo recuperadas as fissuras e trincas nas vigas, lajes e paredes. 


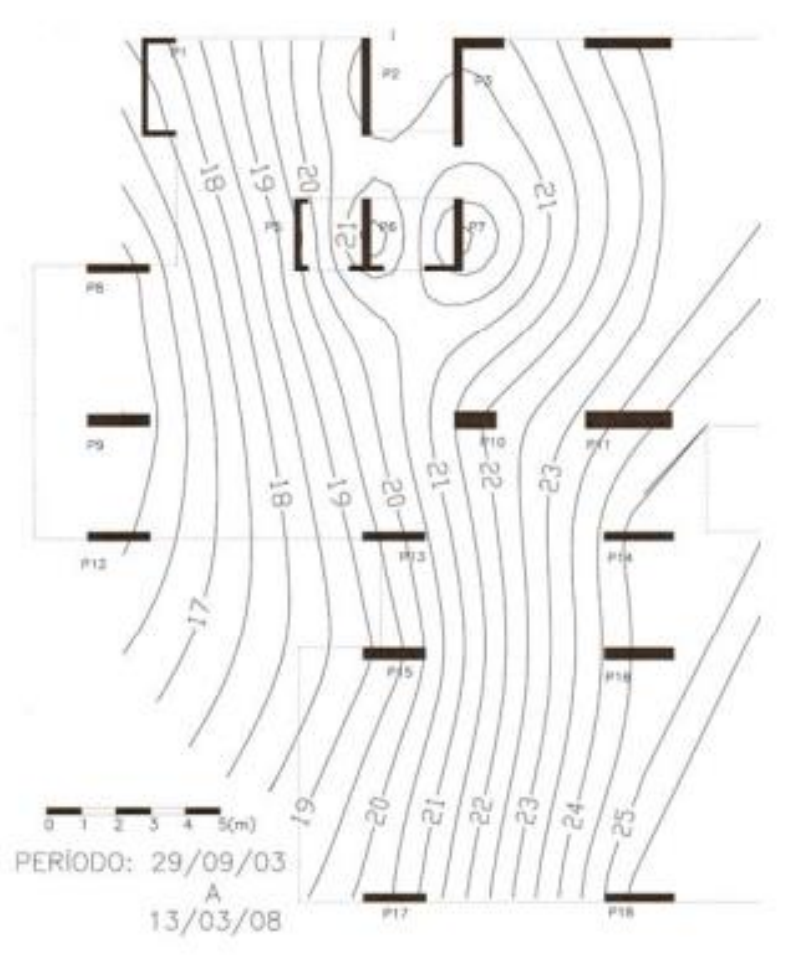

Fig. 13. Curvas de isorecalques da lâmina do prédio na última medição - após o reforço (13/03/2008).

\section{Conclusões}

$\mathrm{O}$ artigo apresenta um caso real de monitoramento dos recalques, onde a instrumentação permitiu identificar o mau desempenho das fundações de um edifício na RMR com 26 lajes. A partir dos resultados do monitoramento do prédio, foi concebido e executado um reforço para as suas fundações. $\mathrm{O}$ reforço foi feito com o prédio ocupado e a estabilização dos recalques foi conseguida.

\section{Agradecimentos}

Os autores agradecem ao condomínio do prédio pela permissão do uso dos dados para a pesquisa, bem como aos engenheiros envolvidos no projeto, execução e monitoramento do reforço das fundações. E também à Escola Politécnica - UPE pela concessão da bolsa.

\section{Referências}

[1] A.D. Gusmão, Prática de Fundações no Recife. Em Gusmão, A. D.; Gusmão Filho, J. A.; Oliveira, e Maia, G. B. (Org.). Geotecnia no Nordeste. Recife,

vol. 1, p. 225-246, 2007

[2] A.D. Gusmão, "Desempenho de Fundações de Edificações", XIII Congresso Brasileiro de Mecânica dos Solos e Engenharia Geotécnica, Curitiba, 2006

[3] J.A. Gusmão Filho, Fundações: do Conhecimento

Geológico à Prática da Engenharia, Editora da UFPE, Recife, 1998. 